\title{
AROMA TERAPI LAVENDER TERHADAP KECEMASAN PASIEN PRA OPERASI KATARAK
}

\author{
Elisa Anderson *, Juwyensi A. Taareluan** \\ *Faculty of Nursing, Universitas Klabat, Manado, Indonesia; **Bachelor of Nursing \\ Faculty, Universitas Klabat, Manado, Indonesia \\ aelisa@unklab.ac.id
}

\begin{abstract}
Surgery is a medical procedure that can trigger anxiety, lavender aromatherapy is one alternative intervention that can be done to overcome this anxiety. The purpose of this study was to analyze the effect of lavender aromatherapy on the anxiety of pre-cataract surgery patients. The research method used was quasiexperimental pre and post-test with control group design. This study was conducted on 30 respondents selected through consecutive sampling techniques and divided into two groups, namely 15 people in the control group and 15 people in the treatment group. The results of this study showed that through the Wilcoxon test found $p=0.008$, there was a significant effect of lavender aromatherapy on anxiety in the treatment group. In the Mann Whitney test found $p=0.006$, there was a significant difference in the effect of lavender aromatherapy on anxiety in the treatment and control groups. Thus, there is a significant effect of the lavender aromatherapy on the anxiety of pre-cataract surgery patients. Nurses can provide aromas of lavender therapy to reduce the anxiety of preoperative patients so that the surgical procedure can work well.
\end{abstract}

Keywords: Anxiety, lavender aromatherapy, preoperative

\begin{abstract}
Abstrak
Operasi merupakan suatu prosedur medis yang bisa mencetuskan kecemasan, terapi aroma lavender merupakan salah satu intervensi alternatif yang dapat dilakukan untuk mengatasi kecemasan tersebut. Tujuan penelitian ini untuk menganalisis pengaruh terapi aroma lavender terhadap kecemasan pasien pra operasi katarak. Metode penelitian yang digunakan adalah quasi-eksperimental dengan pre and post-test with control group design. Penelitian ini dilakukan kepada 30 responden yang dipilih melalui teknik consecutive sampling dan dibagi menjadi dua kelompok, yaitu 15 orang pada kelompok kontrol dan 15 orang pada kelompok perlakuan. Hasil penelitian ini menunjukkan bahwa melalui Wilcoxon test didapati $p=0,008$, terdapat pengaruh yang signifikan terapi aroma lavender terhadap kecemasan pada kelompok perlakuan. Pada Mann Whitney test didapati $p=0,006$, terdapat perbedaan pengaruh yang signifikan terapi aroma lavender terhadap kecemasan pada kelompok perlakuan dan kelompok kontrol. Dengan demikian, terdapat pengaruh yang signifikan terapi aroma lavender terhadap kecemasan pasien pra operasi katarak. Perawat dapat memberikan terapi aroma lavender untuk menurunkan kecemasan pasien pra operasi agar prosedur pembedahan dapat berjalan dengan baik.
\end{abstract}

Kata kunci: Kecemasan, pra operasi, terapi aroma lavender 


\section{Latar belakang}

Katarak merupakan kelainan pada mata yang terjadi akibat adanya perubahan bagian lensa menjadi keruh. Katarak merupakan penyakit degeneratif dan tidak menular tetapi dapat terjadi pada kedua mata secara bersamaan jika tidak ditanggani secara tepat (Novery, 2011). Tindakan pembedahan (operasi) adalah penanganan yang tepat pada katarak untuk memperbaiki visus atau ketajaman penglihatan. Namun demikian, operasi memiliki dampak negatif, yaitu menjadi ancaman atau stresor bagi pasien katarak yang menjalani prosedur pembedahan tersebut. Kurangnya informasi atau informasi yang salah sering kali menjdi pemicu terjadinya kecemasan pada pasien pra operasi katarak (Yanti, Kusumawaty, \& Nugroho, 2017).

Kecemasan merupakan suatu perasaan terkait ketegangan mental yang memberikan reaksi ketidakmampuan mengatasi suatu masalah (Kholil, 2010). Kemampuan seseorang dalam mengatasi masalah sangat bervariasi sehingga saat pasien katarak mengalami cemas sebelum menjalani prosedur pembedahan maka tingkat kecemasannya pun berbeda-beda untuk setiap individunya. Hal ini dapat terlihat dari respon fisiologis dan psikologis pasien pra operasi. Keliat, Wijoyo, dan Susanti (2011) mengungkapkan bahwa kecemasan dianggap berbahaya saat individu tidak dapat mengatasi kecemasannya secara tepat sehingga menimbulkan ketidakmampuan dalam menyesuaikan diri dengan lingkungan dan dapat mengganggu kesehatannya. Namun demikian, terdapat beberapa cara untuk mengatasi atau mengendalikan kecemasan, di antaranya adalah terapi aroma lavender.

Terapi aroma lavender merupakan salah satu terapi nonfarmakologi yang bersifat complementary and alternative medicine (CAM). Terapi aroma lavender adalah salah satu metode terapi keperawatan yang menggunakan bahan seperti cairan tanaman yang mudah menguap atau dikenal sebagai minyak esensial dan bertujuan untuk mempengaruhi suasana hati ataupun kesehatan seseorang (Purwanto, 2013). Kandungan senyawa kimia dari minyak esensial terapi aroma lavender dapat mempengaruhi aktifitas kerja otak melalui sistem saraf yang berhubungan dengan indera penciuman. Respon ini akan merangsang dan meningkatkan aktivitas neurotransmitter untuk pemulihan kondisi psikologis seperti emosi, perasaan, pikiran, dan keinginan (Jaelani, 2009). Minyak lavender mempunyai banyak potensi, seperti kandungan linalool dan linalool asetat dengan jumlah sekitar 30-60\% dari total berat minyak. Kandungan aktif linalool ini berguna untuk menciptakan kondisi relaksasi atau mengurangi kecemasan (Nuraini, 2014).

\section{Metode}

Metode dalam penelitian ini adalah quasi eksperimental pre and post-test with control group design, yaitu melakukan identifikasi pada variabel dependen (kecemasan) sebelum dan sesudah perlakuan (terapi aroma lavender) di kelompok kontrol serta perlakuan, kemudian menganalisis pengaruh pemberian terapi aroma lavender terhadap kecemasan (Dharma, 2013; Notoatmodjo, 2010). Sampel dalam penelitian ini berjumlah 30 responden yang merupakan pasien pra operasi katarak di Rumah Sakit Mata Sulawesi Utara dan dibagi menjadi dua kelompok, yaitu 15 orang untuk kelompok control dan 15 orang untuk kelompok perlakuan. Teknik pemilihan sampel yang digunakan adalah teknik consecutive sampling. Prosedur pemberian terapi aroma lavender adalah memberikan tiga tetes minyak lavender ke dalam masker dan meminta responden untuk menghirupnya selama 15 menit (Koensoemardiyah, 2009).

Instrument yang digunakan untuk mengukur kecemasan adalah Hamilton Rating 
Scale for Anxiety (HRS-A), yang terdiri dari 14 gejala dan masing-masing gejala diberi penilaian 0-4 dengan dengan penjelasan nilai 0 tidak ada gejala atau keluhan, 1 gejala ringan, 2 gejala sedang, 3 gejala berat, dan 4 gejala berat sekali. Intepretasi instrumen HRSA berdasarkan penilaian total, yaitu skor $<14$ tidak ada kecemasan, skor 14-20 mengalami kecemasan ringan, skor 21-27 kecemasan sedang, skor 28-41 kecemasan berat, dan skor 42-56 kecemasan berat sekali (Hawari, 2008).

\section{Hasil dan Pembahasan}

Analisis bivariat digunakan untuk mencapai tujuan penelitian, yaitu menganalisis pengaruh terapi aroma lavender terhadap kecemasan pasien pra operasi katarak. Analisis bivariat dalam penelitian ini mengidentifikasi data variabel dependen (kecemasan) melalui kuesioner HRS-A, baik sebelum dan sesudah pemberian terapi aroma lavender pada kelompok kontrol dan perlakuan, kemudian melihat pengaruhnya melalui perhitungan statistik Wilcoxon test dan Mann Whitney test.

Tabel 1 Hasil analisis pengaruh terapi aroma lavender terhadap kecemasan pada kelompok perlakuan

\begin{tabular}{lcccc}
\hline & \multicolumn{4}{c}{ Kelompok Perlakuan } \\
\cline { 2 - 5 } & \multicolumn{3}{c}{ Pre-test } & \multicolumn{3}{c}{ Post-test } \\
\cline { 2 - 5 } & $f$ & $\%$ & $f$ & $\%$ \\
\hline Cemas ringan & 13 & $87 \%$ & 9 & $60 \%$ \\
Cemas sedang & 2 & $13 \%$ & $60 \%$ \\
Cemas berat & 15 & $100 \%$ & 15 & $100 \%$ \\
Total & \multicolumn{4}{c}{0,008} \\
Sig.(2-tailed) & \multicolumn{5}{c}{} \\
\hline
\end{tabular}

Tabel 1 menunjukkan bahwa hasil pretest kelompok perlakuan didapati $13(87 \%)$ responden mengalami cemas sedang dan 2 (13\%) responden mengalami cemas berat. Sedangkan hasil posttest kelompok perlakuan didapati $9(60 \%)$ responden mengalami cemas sedang dan $6(40 \%)$ responden mengalami cemas ringan. Data tersebut menerangkan bahwa terjadi penurunan kecemasan pada kelompok perlakuan setelah diberikan terapi aroma lavender. Hal ini juga dikuatkan dengan nilai $p=0,008$ pada Wilcoxon test yang berarti terdapat pengaruh yang bermakna terapi aroma lavender terhadap kecemasan pasien pra operasi katarak. Pada kelompok perlakuan, semua pasien pra operasi katarak mengalami cemas dengan kategori sedang hingga berat. Setelah diberikan terapi aroma lavender selama 15 menit maka kecemasan pesien tersebut menurun pada kategori ringan ke sedang, tidak ada lagi yang mengalami kecemasan berat. Dengan demikian, terapi aroma lavender dapat digunakan untuk mengendalikan kecemasan khususnya pada pasien pra operasi katarak.

Penelitian ini sejalan dengan penelitian yang dilakukan oleh Arwani, Sriningsih dan Rodhi (2013) mendapatkan temuan hasil bahwa terdapat pengaruh pemberian aromaterapi terhadap tingkat kecemasan pasien sebelum operasi dengan anastesi spinal di RS Tugu Semarang $(p=0,00)$. Penelitian Dila, Putra, dan Arifin (2017) juga mendapatkan kesimpulan bahwa terapi aroma lavender memiliki pengaruh yang signifikan dalam penurunan kecemasan ibu pra operasi sectio caesarea di rumah sakit bersalin ( $p=$ $0,000)$. Kedua temuan ini menguatkan pengaruh terapi aroma lavender dapat digunakan untuk mengurangi kecemasan pasien pra operasi.

Terapi aroma lavender dihirup melalui organ penciuman diterima oleh reseptor sistem saraf yang terdapat pada rambut-rambut halus di hidung. Pada saat molekul dari aroma lavender itu menempel, suatu pesan kimia ditransmisikan melalui saraf olfactory ke dalam sistem limbik. Hipotalamus yang berperan sebagai regulator segera memunculkan pesan-pesan tersebut ke bagian otak serta bagian tubuh yang lain. Pesan diterima kemudian diubah menjadi tindakan 
untuk melepaskan senyawa yang menimbulkan reaksi rileks (Koensoemardiyah, 2009).

Tabel 2 Hasil analisis pengaruh terapi aroma lavender terhadap kecemasan pada kelompok kontrol dan perlakuan

\begin{tabular}{lcccc}
\hline & $\mathrm{N}$ & Rerata & $\mathrm{Z}$ & Sig (2-tailed) \\
\hline Kontrol & 15 & 19 & \multirow{2}{*}{2,742} & 0,006 \\
Intervensi & 15 & 12 & & \\
\hline
\end{tabular}

Tabel 2 menunjukkan bahwa rerata nilai posttest pada kelompok kontrol adalah 19 yang berarti responden mengalami kecemasan ringan dan rerata nilai posttest pada kelompok perlakuan adalah 12 yang berarti responden tidak mengalami kecemasan. Data ini menyatakan bahwa kecemasan pada kelompok perlakuan lebih baik dibandingkan dengan kelompok kontrol. Hal ini juga dikuatkan dengan nilai $p=0,006$ pada Mann Whitney test yang berarti terdapat perbedaan yang signifikan pengaruh terapi aroma lavender terhadap kecemasan pasien pra operasi katarak pada kelompok perlakuan dan kelompok kontrol. Hal ini sejalan dengan penelitian yang dilakukan oleh Fatmawati (2016) dengan judul pengaruh relaksasi progresif dan aromaterapi lavender terhadap penurunan kecemasan pada pasien preoperasi dengan spinal anastesi, temuan hasil menyatakan bahwa terdapat perbedaan kecemasan yang signifikan antara kelompok eksperimen dengan kelompok kontrol dengan $p=0,019$.

Pada saat pasien katarak dinyatakan dokter untuk dilakukan prosedur pembedahan terhadap dirinya, maka pasien menganggap prosedur itu adalah bahaya yang mengancaam dirinya atau suatu prosedur yang dapat mengancam integritas dirinya sehingga muncullah perasaan cemas dari prosedur pembedahan yang direncanakan. Kecemasan pasien ini dapat terlihat dari tanda dan gejala pada aspek fisik, kognitif, perilaku, maupun emosi (Rochman, 2010). Perawat yang berkompeten dapat melihat atau menemukan tanda dan gejala tersebut melalui pengkajian yang dilakukan. Secara alami tubuh merespon kecemasan yang dialaminya dan berusaha untuk mengendalikannya. Selain itu, secara prosedural perawat memberikan tindakan keperawatan untuk mengatasi kecemasan yang dialami oleh pasiennya. Adapun tindakan keperawatan tersebut adalah membina hubungan saling percaya agar pasien merasa aman dan nyaman saat berinteraksi; mengucapkan salam terapeutik, berjabat tangan, menjelaskan tujuan interaksi, membuat kontrak topik, waktu dan tempat setiap kali bertemu; membantu pasien mengenal kecemasannya dengan mengidentifikasi dan menguraikan perasaannya (Donsu, 2017). Kedua hal ini yang sama-sama diterima oleh pasien pra operasi katarak pada kelompok perlakuan dan kelompok kontrol sehingga pada pada posttest kelompok kontrol memiliki rerata kecemasan ringan. Pada kelompok perlakuan, selain mendapatkan perawatan rutinitas dan memiliki sistem regulasi kecemasan tubuh, kelompok perlakuan diberikan terapi aroma lavender selama 15 menit. Kemudian, pada posttest kelompok perlakuan memiliki rerata tidak mengalami kecemasan. Dengan demikian, aroma lavender dapat dijadikan terapi untuk menurunkan atau mengatasi kecemasan khususnya pada pasien pra operasi.

\section{Simpulan dan Rekomendasi}

Berdasarkan temuan hasil yang telah dianalisis melalui perhitungan statistic pengolahan data dengan menggunakan uji statistik Wilcoxon test dan Mann Whitney test, maka dapat disimpulkan bahwa terdapat pengaruh yang bermakna terapi aroma lavender terhadap kecemasan pasien pra operasi katarak dengan nilai $p=0,008$, terdapat perbedaan yang bermakna terapi aroma lavender terhadap kecemasan pasien pra 
operasi katarak pada kelompok perlakuan dan kelompok kontrol dengan $p=0,006$.

Temuan hasil penelitian ini, yaitu terapi aroma lavender dapat direkomendasikan kepada petugas kesehatan khususnya perawat untuk dijadikan intervensi keperawatan mandiri pada saat menghadapi pasien pra operasi yang mengalami kecemasan.

\section{Daftar Pustaka}

Arwani, Sriningsih., \& Rodhi. (2013).

Pengaruh pemberian aromaterapi terhadap tingkat kecemasan pasien sebelum operasi dengan anestesi spinal di RS Tuguh Semarang. Jurnal keperawatan jiwa, 1, 129-134.

Ary, H. (2010). Sosiologi Pendidikan. Jakarta: PT Rineka Cipta.

Dharma, K. K. (2013). Metodologi penelitian keperawatan. Jakarta: Trans Info Media.

Dila, R. D., Putra, F., \& Arifin, F. R. (2017).

Pengaruh aromaterapi lavender terhadap penurunan kecemasan ibu pre operasi sectio caesarea di rumah sakit bersalin. Caring Nursing Journal, 1, 51-56.

Donsu, J. D. (2017). Psikologi Keperawatan Aspek-aspek Psikologi dan Konsep Dasar Psikologi Teori Perilaku Manusia. Yogyakarta: Pustaka baru press.

Fatmawati, P. D. (2016). Pengaruh relaksasi progresif dan aromaterapi lavender terhadap penurunan kecemasan pada pasien preoperasi dengan spinal anastesi.Skripsi. Publised
Hawari, D. (2008). Manajemen Stres, Cemas, dan Depresi. Jakarta: Fakultas kedokteran Universitas Indonesia.

Jaelani. (2009). Aromaterapi. Jakarta: Pustaka populer obor.

Kaliat, B. A., Wijoyo, A.,\& Susanti, H. (2011). Manajemen Kasus Gangguan Jiwa. Jakarta: EGC.

Kholil, L. R. (2010). Kesehatan Mental. Purwokerto: Fajar Media Press.

Koensoemardiyah. (2009). Aromaterapi Untuk Kesehatan, kebugaran, dan kecantikan. Yogyakarta: Lily.

Notoatmodjo, S. 2010. Metodologi Penelitian Kesehatan. Jakarta: Rineka Cipta.

Novery, A. (2011). Faktor-Faktor Yang Berhubungan dengan Kejadian Katarak Pada Pasien Di Poli Matarsud Pariaman.

KTI.

Akademi.Skripsi.Publised

Nuraini, D. (2014). Aneka Manfaat Bunga Untuk Kesehatan. Yogyakarta: Gaya Media.

Purwanto, B. (2013). Herbal dan

Keperawatan Komplementer (teori, praktik, hukum dalam asuhan keperawatan). Yogyakarta: Nuhu Medika.

Rochman, K. (2010). Kesehatan Mental. Purwokerto: Fajar Media Press.

Yanti, S., Kusumawaty, J., \& Nugroho, A. (2017). Tingkat kecemasan pasien pre operasi katarak diruang bedah RSUD Kabupaten Ciamis. Motorik,12.33-38. 